\title{
Effects of smoking and alcohol consumption on 5-fluorouracil-related metabolic enzymes in oral squamous cell carcinoma
}

\author{
TOMOMI YAMASHITA ${ }^{1,2}$, KEIZO KATO ${ }^{2}$, NGUYEN KHANH LONG ${ }^{2}$, HIROKI MAKITA ${ }^{2}$, \\ KAZUHIRO YONEMOTO ${ }^{2}$, KAZUKI IIDA ${ }^{2}$, NARITAKA TAMAOKI ${ }^{2}$, \\ DAIJIRO HATAKEYAMA ${ }^{2}$ and TOSHIYUKI SHIBATA ${ }^{2}$
}

\author{
${ }^{1}$ Department of Dentistry and Oral Surgery, Kouseiren Takaoka Hospital, Takaoka, Toyama 933-8555; \\ ${ }^{2}$ Department of Oral and Maxillofacial Surgery, Graduate School of Medicine, Gifu University, Gifu, Gifu 501-1194, Japan
}

Received August 7, 2013; Accepted February 18, 2014

DOI: $10.3892 / \mathrm{mco} .2014 .267$

\begin{abstract}
Lifestyle, particularly smoking and alcohol consumption, may induce and/or inhibit drug metabolism. In order to reveal the effects of smoking and alcohol consumption on the 5-fluorouracil (5-FU)-related metabolic enzymes, namely thymidylate synthase, dihydropyrimidine dehydrogenase (DPD; a sole catabolic enzyme of 5-FU), orotate phosphoribosyl transferase (OPRT) and thymidine phosphorylase, in oral squamous cell carcinomas, the mRNA expression of these enzymes was investigated in 29 surgical specimens and compared by the Brinkman index and drinking years. The surgical specimens were divided into normal and tumor regions and were independently analyzed using quantitative reverse transcription-polymerase chain reaction. There was a significantly positive correlation between DPD mRNA expression in these tissues and Brinkman index/drinking years, with OPRT mRNA expression being significantly correlated to the Brinkman index in tumor tissues. These results revealed that lifestyle habits, including smoking and alcohol consumption, may vary the activity of the 5-FU-related metabolic enzymes. DPD is the initial and rate-limiting enzyme in the catabolic pathway of 5-FU. Therefore, smoking and alcohol consumption may reduce the anticancer activity of 5-FU, possibly through the induction of DPD activity.
\end{abstract}

Correspondence to: Dr Toshiyuki Shibata, Department of Oral and Maxillofacial Surgery, Graduate School of Medicine, Gifu University, 1-1 Yanagido, Gifu, Gifu 501-1194, Japan

E-mail: shibat@gifu-u.ac.jp

Abbreviations: OSCC, oral squamous cell carcinoma; TS, thymidylate synthase; DPD, dihydropyrimidine dehydrogenase; OPRT, orotate phosphoribosyl transferase; TP, thymidine phosphorylase; 5-FU, 5-fluorouracil; UFT, tegafur/uracil

Key words: smoking, alcohol, Brinkman index, 5-fluorouracil metabolic enzymes, dihydropyrimidine dehydrogenase, oral squamous cell carcinoma

\section{Introduction}

5-Fluorouracil (5-FU) is an anticancer agent widely used in the treatment of several types of cancer, including gastrointestinal, mammary, head and neck, non-small-cell lung and oral cancers. The effects of 5-FU are closely associated with the activity of its metabolic enzymes. The 5-FU-related enzymes, namely thymidylate synthase (TS), dihydropyrimidine dehydrogenase (DPD), orotate phosphoribosyl transferase (OPRT) and thymidine phosphorylase (TP), play a significant role in the anticancer effects of 5-FU (1-15). Therefore, evaluation of the mRNA expression levels of these enzymes may determine the desirable efficiency and concomitant side effects of 5-FU. From this point of view, the correlation between enzyme expression and anticancer effects has been extensively investigated $(3,4,8,9,11,16)$. Although there are controversial points, it was suggested that the high expression of DPD in tumor tissues may reduce the anticancer effects of 5-FU (8-10,17).

Cigarette smoking is a major risk factor for the development of squamous cell carcinoma of the head and neck. Additionally, alcohol consumption has long been known as a risk factor for head and neck cancers (18). Previous evidence indicates that patients with head and neck cancers, including oral cancers, are highly likely to lead such lifestyles. Furthermore, it was reported that lifestyle, particularly smoking and/or alcohol consumption, may modulate drug metabolism through enzyme induction and/or inhibition (19-21). However, there is currently no available report regarding the effects of these lifestyle habits on the status of 5-FU-related metabolic enzymes. In the present study, in order to elucidate the effects of smoking and alcohol consumption on the 5-FU-related metabolic enzymes, the expression status of TS, DPD, TP and OPRT was investigated in oral squamous cell carcinoma (OSCC) and adjacent normal tissues.

\section{Materials and methods}

Patient population. A total of 29 patients who underwent surgical resection of primary OSCC at the Department of Oral and Maxillofacial Surgery, Gifu University Hospital (Gifu, 
Japan) between March, 2002 and October, 2004 were included in the present study (Table I). In total, 15 patients were smokers and their average Brinkman index, calculated by the numbers of cigarettes smoked per day multiplied by the smoking years, was 784.5 (range, 140-2,100). Additionally, 13 patients had a habit of alcohol consumption and their average number of drinking years was 41.2 (12-63 years).

This study was approved by the Institutional Review Board of Gifu University and all the participants provided written informed consent.

RNA extraction and cDNA synthesis. Two tissue specimens, weighing $\sim 3 \mathrm{mg}$ and measuring $3 \mathrm{~mm}$ in length each, were obtained from tumor and adjacent normal tissues resected during surgery. Efforts were made to minimize the time interval between surgery and freezing of the samples.

Total RNA was isolated using an RNeasy mini kit (Qiagen, Inc., Chatsworth, CA, USA), and DNase treatment was performed with the RNase-Free DNase set (Qiagen, Inc.) according to the manufacturer's instructions. Following RNA isolation, cDNA was prepared from each sample using SuperScript II Reverse Transcriptase (Invitrogen, Co., Carlsbad, CA, USA). Reverse transcription with $\leq 4 \mu \mathrm{g}$ of total RNA was performed in a total volume of $1 \mu 1$ containing $500 \mu \mathrm{g} / \mathrm{ml}$ oligo(dT) in $250 \mathrm{mM}$ Tris- $\mathrm{HCl}(\mathrm{pH} \mathrm{8.3),} 375 \mathrm{mM} \mathrm{KCl}$, $15 \mathrm{mM} \mathrm{MgCl} l_{2}, 0.1 \mathrm{M}$ dithiothreitol and $1 \mu 1$ deoxyribonucleotide triphosphates. Initially, the total RNA solution and oligo(dT) mixture was heated at $65^{\circ} \mathrm{C}$ for $5 \mathrm{~min}$ and immediately chilled on ice, followed by the addition of the other reagents. First strand cDNAs were obtained and dissolved in $20 \mu$ distilled water.

Quantitative reverse transcription-polymerase chain reaction ( $q R T-P C R$ ). The mRNA levels of TS, DPD, OPRT and TP were evaluated by qRT-PCR (TaqMan PCR) using an ABI Prism 7700 sequence detector (Perkin-Elmer Applied Biosystems, Foster City, CA, USA). The $\beta$-actin gene was used as an endogenous control gene. The primers and TaqMan probes for each gene were designed based on the nucleotide sequence of human TS, DPD, OPRT and TP (Table II). The PCR mixture contained $10 \mu 1$ of each appropriately diluted cDNA sample (standard curve points and patient samples), $200 \mathrm{nM}$ forward primer, $200 \mathrm{nM}$ reverse primer, $100 \mathrm{nM}$ TaqMan probe and $12.5 \mu 1$ TaqMan Universal PCR Master Mix (Perkin-Elmer Applied Biosystems) in a final volume of $25 \mu \mathrm{l}$. The PCR profile consisted of incubation at $94^{\circ} \mathrm{C}$ for $2 \mathrm{~min}$, followed by incubation at $95^{\circ} \mathrm{C}$ for $10 \mathrm{~min}$ and 40 cycles of amplification at $95^{\circ} \mathrm{C}$ for $15 \mathrm{~s}$ and at $60^{\circ} \mathrm{C}$ for $1 \mathrm{~min}$. The expression of the $\beta$-actin gene was used as an internal standard and the relative gene expression was calculated by determining the ratio between the amount of the PCR product of the 5-FU-related metabolic enzyme genes and the $\beta$-actin gene.

Statistical analysis. The association between smoking and drinking and the mRNA levels of the 5-FU-related metabolic enzymes were compared using the Kruskal-Wallis rank test. The mRNA levels of the 5-FU-related metabolic enzymes were compared by the Brinkman index/drinking years using Pearson's correlation coefficient. $\mathrm{P}<0.05$ was considered to indicate a statistically significant difference for each analysis.
Table I. Clinicopathological characteristics of 29 OSCC patients.

\begin{tabular}{|c|c|}
\hline Characteristics & No. $(\%)$ \\
\hline \multicolumn{2}{|l|}{ Age, years } \\
\hline Mean \pm SD & $68.8 \pm 13.4$ \\
\hline Range & $39-91$ \\
\hline \multicolumn{2}{|l|}{ Gender } \\
\hline Male & $16(55.2 \%)$ \\
\hline Female & $13(44.8 \%)$ \\
\hline \multicolumn{2}{|l|}{$\mathrm{T}$} \\
\hline 1 & $5(17.2 \%)$ \\
\hline 2 & $13(44.8 \%)$ \\
\hline 3 & $5(17.2 \%)$ \\
\hline 4 & $6(20.8 \%)$ \\
\hline \multicolumn{2}{|l|}{$\mathrm{N}$} \\
\hline 0 & $24(82.8 \%)$ \\
\hline 1 & $4(13.8 \%)$ \\
\hline 2 & $1(3.4 \%)$ \\
\hline \multicolumn{2}{|l|}{ Stage } \\
\hline $\mathrm{I}$ & $5(17.2 \%)$ \\
\hline II & $10(34.4 \%)$ \\
\hline III & $8(27.6 \%)$ \\
\hline IV & $6(20.8 \%)$ \\
\hline \multicolumn{2}{|c|}{ Histopathological grading } \\
\hline G1 & $24(82.8 \%)$ \\
\hline $\mathrm{G} 2$ & $5(17.2 \%)$ \\
\hline \multicolumn{2}{|c|}{ Anneroth's classification } \\
\hline I & $4(13.8 \%)$ \\
\hline II & $17(58.6 \%)$ \\
\hline III & $8(27.6 \%)$ \\
\hline \multicolumn{2}{|l|}{ Tumor location } \\
\hline Buccal mucosa & 5 \\
\hline Upper gum & 3 \\
\hline Lower gum & 8 \\
\hline Tongue & 7 \\
\hline Floor of mouth & 6 \\
\hline \multicolumn{2}{|l|}{ Smoking } \\
\hline No & $14(48.3 \%)$ \\
\hline Yes & $15(51.7 \%)$ \\
\hline \multicolumn{2}{|l|}{ Brinkman index } \\
\hline Mean \pm SD & $784.5 \pm 523.4$ \\
\hline Range & $140-2,100$ \\
\hline \multicolumn{2}{|l|}{ Drinking } \\
\hline No & $16(55.2 \%)$ \\
\hline Yes & $13(44.8 \%)$ \\
\hline \multicolumn{2}{|l|}{ Drinking years } \\
\hline Mean \pm SD & $41.2 \pm 16.6$ \\
\hline Range & $12-63$ \\
\hline
\end{tabular}

OSCC, oral squamous cell carcinoma; SD, standard deviation.

\section{Results}

Effect of smoking on mRNA expression of 5-FU-related metabolic enzymes. The P-values reflecting the correlation between the Brinkman index and mRNA expression of the 5-FU-related 
Table II. Sequence of quantitative RT-PCR primers and sequence-specific probes for target genes.

\begin{tabular}{ll} 
Target gene & \\
\hline TS & \\
Sense & ATTimer sequence $\left(5^{\prime} \rightarrow 3^{\prime}\right)$ \\
Antisense & TCGAAGAATCCTGAGCTTTGG \\
TaqManProbe & FAM-AAAATTCAGCTTCAGCGAGAACCCAGACC-TAMRA \\
DPD & \\
Sense & TCCCCAAAAGGCCTATTCCT \\
Antisense & TGCTCAATTCACCAAATGTTCC \\
TaqManProbe & FAM-CCATCAAGGATGTAATAGGAAAAGCACTGCAG-TAMRA \\
TP & \\
Sense & \\
Antisense & GAGTCTATTCCTGGATTCAATGTCATC \\
TaqManProbe & CCCACGATACAGCAGCCC \\
OPRT & FAM-CAGATGCAAGTGCTGCTGGACCAGG-TAMRA \\
Sense & \\
Antisense & ACTACACTAGAGCAGCGGTTAGAATG \\
TaqManProbe & AACTGAACTCCTGGAGTCAAGTGA \\
\hline
\end{tabular}

The probes were labeled with a reporter dye (FAM), situated at the 5'- end of the oligonucleotide, and a quencher dye (TAMRA), located at the 3'- end. RT-PCR, reverse transcription-polymerase chain reaction; TS, thymidylate synthase; DPD, dihydropyrimidine dehydrogenase; TP, thymidine phosphorylase; OPRT, orotate phosphoribosyl transferase.

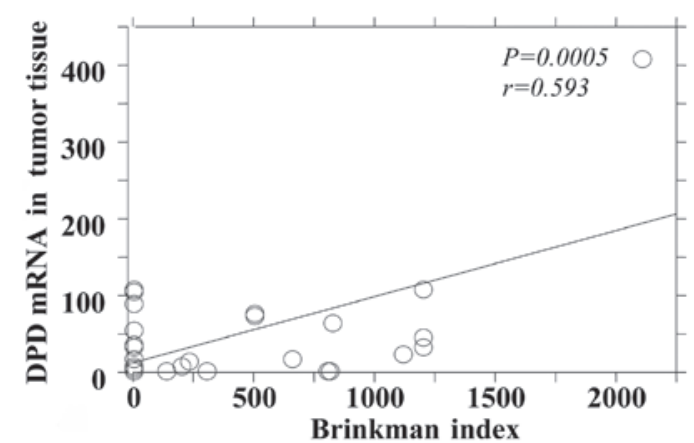

Figure 1. Brinkman index and dihydropyrimidine dehydrogenase (DPD) mRNA level in tumor tissue.

metabolic enzymes in tumor and adjacent normal tissues are summarized in Table III. There was no significant difference between the mRNA expression levels of TS and TP in tumor and adjacent normal tissues, although there was a significant positive correlation between the Brinkman index and the DPD mRNA expression in tumor and adjacent normal tissues (Figs. 1 and 2). The OPRT mRNA expression was found to be significantly correlated with the Brinkman index in tumor tissues only (Fig. 3).

Effect of alcohol consumption on mRNA expression of 5-FU-related metabolic enzymes. The P-values reflecting the correlation between drinking years and the mRNA expression of the 5-FU-related metabolic enzymes in tumor and adjacent normal tissues are summarized in Table IV. There was no significant difference between the mRNA expression levels of TS, OPRT and TP in tumor and adjacent normal tissues, although there was a significant positive correlation between

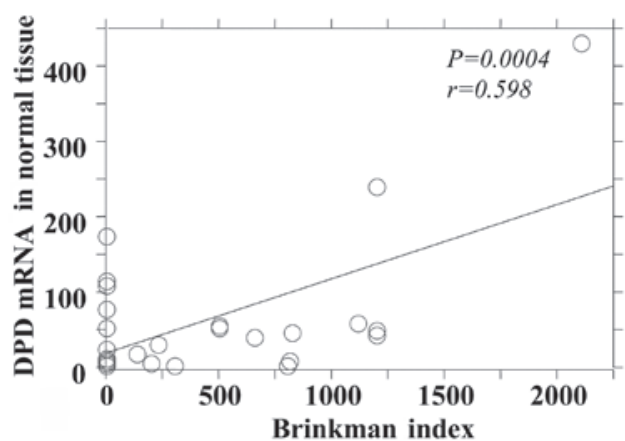

Figure 2. Brinkman index and dihydropyrimidine dehydrogenase (DPD) mRNA level in normal tissue.

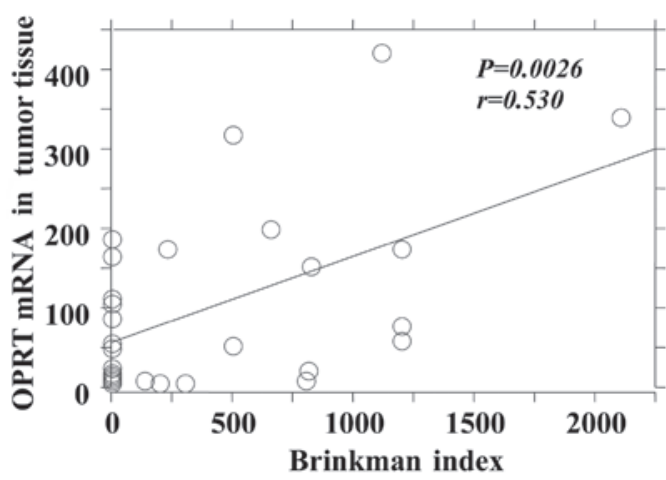

Figure 3. Brinkman index and orotate phosphoribosyl transferase (OPRT) mRNA level in tumor tissue.

drinking years and the DPD mRNA expression in tumors and adjacent normal tissues (Figs. 4 and 5). 
Table III. P-values and correlation coefficients between the Brinkman index and the mRNA expression of 5-FU-related metabolic enzymes.

\begin{tabular}{lcc}
\hline Enzymes & P-value & Correlation coefficient \\
\hline TS & & \\
Tumor & 0.5289 & 0.123 \\
Normal & 0.8253 & 0.048 \\
DPD & & \\
Tumor & 0.0005 & 0.593 \\
Normal & 0.0004 & 0.598 \\
OPRT & & \\
Tumor & 0.0026 & 0.530 \\
Normal & 0.097 & 0.314 \\
TP & & \\
Tumor & 0.3338 & 0.187 \\
Normal & 0.5064 & 0.130 \\
\hline
\end{tabular}

5-FU, 5-fluorouracil; TS, thymidylate synthase; DPD, dihydropyrimidine dehydrogenase; OPRT, orotate phosphoribosyl transferase; $\mathrm{TP}$, thymidine phosphorylase.

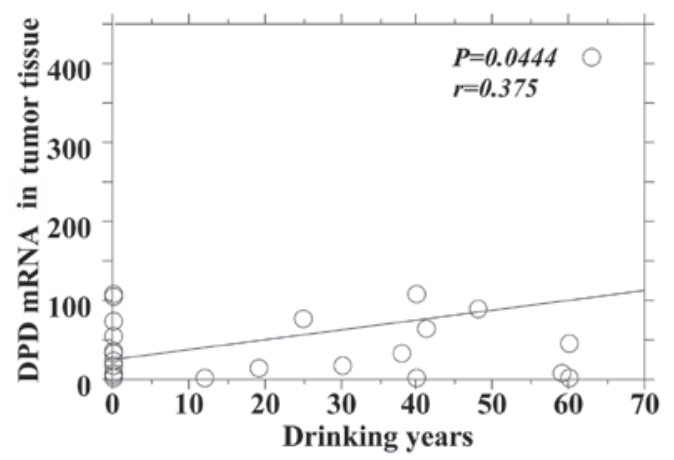

Figure 4. Drinking years and dihydropyrimidine dehydrogenase (DPD) mRNA level in tumor tissue.

\section{Discussion}

5-FU is metabolized into two different active forms, 5-fluorodeoxyuridine monophosphate (FdUMP) and 5-fluorouridine triphosphate, which inhibit DNA synthesis and RNA function, respectively. FdUMP and its coenzyme, 5,10-methylene terahydrofolate, form a covalent ternary complex with the DNA-synthesizing enzyme TS (1). This complex inhibits the conversion of deoxyuridine monophosphate to deoxythymidine monophosphate, which is an essential step of DNA synthesis, thus exerting anticancer effects (2). Consequently, the overexpression of TS possibly decreases the inhibitory effect of 5-FU on DNA synthesis; several studies suggested that high amounts of TS in tumor cells may decrease the efficiency of 5-FU and lead to the development of drug resistance (3-7).

DPD is the initial and rate-limiting enzyme in the catabolic pathway of 5-FU. Therefore, DPD may reduce the anticancer effects of 5-FU in tumor cells and several studies indicated that the level of DPD expression is significantly correlated with resistance to 5-FU (8-10).
Table IV. P-values and the correlation coefficients between the drinking years and the mRNA expression of 5-FU-related metabolic enzymes.

\begin{tabular}{lcc}
\hline Enzymes & P-value & Correlation coefficient \\
\hline TS & & \\
Tumor & 0.6687 & 0.084 \\
Normal & 0.3528 & 0.818 \\
DPD & & \\
Tumor & 0.0444 & 0.375 \\
Normal & 0.0202 & 0.426 \\
OPRT & & \\
Tumor & 0.2879 & 0.205 \\
Normal & 0.3902 & 0.167 \\
TP & & \\
Tumor & 0.1286 & 0.290 \\
Normal & 0.9183 & 0.020 \\
\hline
\end{tabular}

5-FU, 5-fluorouracil; TS, thymidylate synthase; DPD, dihydropyrimidine dehydrogenase; OPRT, orotate phosphoribosyl transferase; $\mathrm{TP}$, thymidine phosphorylase.

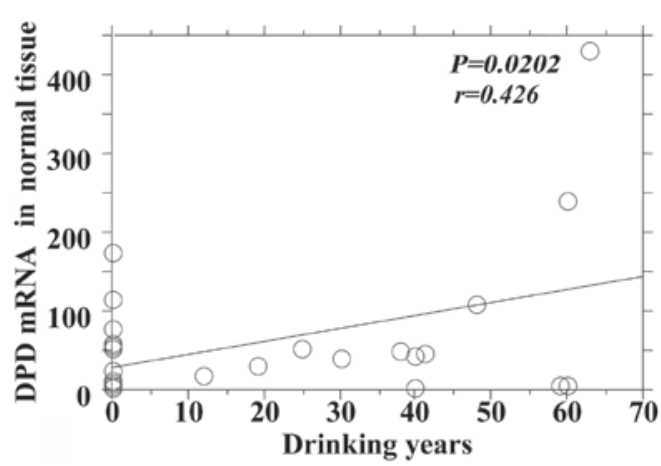

Figure 5. Drinking years and dihydropyrimidine dehydrogenase (DPD) mRNA level in normal tissue.

OPRT is the first key enzyme in the phosphorylation of 5-FU, converting 5-FU to 5-fluorouridine monophosphate. OPRT is considered to predominantly inhibit RNA synthesis. Thus, it was reported that high amounts of intratumoral OPRT are correlated with sensitivity to 5-FU (11-13).

TP catalyzes the reversible conversion of 5-FU to 5-deoxy-5-fluorouridine and high expression of this enzyme in tumors is correlated with a high response rate to 5-deoxy5-fluorouridine (14,15) (Fig. 1). Thus, the anticancer effects of 5-FU are closely correlated with the activity of its metabolic enzymes, which have been extensively investigated in oral cancers $(3,4,8,9,11,16)$.

A previous clinical study demonstrated that neoadjuvant chemotherapy may affect the 5-FU-related metabolic enzyme status, although the effects of lifestyle habits, including smoking and alcohol consumption, on 5-FU-related metabolic enzymes were not investigated (22). The results of the present study on mRNA analysis indicated that mRNA expression of TS, TP and OPRT in tumor and adjacent normal tissues was not affected by smoking and alcohol 
consumption. However, the mRNA expression of DPD was dependently enhanced in tumor and adjacent normal tissues by both the Brinkman index and alcohol drinking years. DPD is the initial and rate-limiting enzyme that catabolizes 5 -FU in the liver. Therefore, DPD in tumor cells may reduce the anticancer effects of 5-FU and several studies reported that the levels of DPD expression are significantly correlated with resistance to 5-FU $(8-10,17)$.

Lifestyle habits, including cigarette smoking and alcohol consumption, are known to affect drug treatment through pharmacokinetic and pharmacodynamic mechanisms (19-21,23). Cigarette smoking contains thousands of different compounds, some of which are known carcinogens. In addition, exposure to these compounds may facilitate the development of detoxification enzyme systems and cigarette smoking is a known enzyme inducer (19). Smoking may reduce the intake and serum concentrations of nutrients, such as $\beta$-carotene and vitamin A, which are known to protect against the development of epithelial cancers. Smoking is also associated with an increased blood carboxyhemoglobin concentration, which causes a leftward shift in the hemoglobin-oxygen dissociation curve, leading to relative tissue hypoxia and alterations in the enzyme status (23).

Alcohol is metabolized through several processes or pathways in the liver. The alcohol dehydrogenase pathway, the microsomal ethanol oxidizing system and the catalase pathway, play significant roles in alcohol metabolism. The alcohol molecule is metabolized to aldehyde and, subsequently, to acetate, which is broken down into water and carbon dioxide and easily eliminated from the body. As regards the effect of alcohol on these enzymes, it was previously reported that alcohol interacts with certain membrane-associated signal transduction systems, resulting in positive and/or negative regulation of adenylate cyclase, phospholipase $\mathrm{C}$ and phospholipase A2; furthermore, it was reported that alcohol may repress TS and thymidine kinase activity following hepatectomy $(20,21)$.

In the present study, the DPD mRNA expression in tumor and adjacent normal tissues was found to be correlatively enhanced by the Brinkman index and drinking years. It is known that the DPD status corresponds to the alternations in the 5-FU pharmacokinetic profile. For example, DPD deficiency may lead to severe 5-FU-associated toxicities and, in theory, a DPD excess may reduce the therapeutic effects of 5-FU. It is suggested that the diversities in the DPD status originate in individual DPD genomic polymorphism and may be modulated by smoking and alcohol consumption, which may affect DPD functionality in the liver.

The exact mechanism underlying the modulation of the 5-FU metabolic enzymes by lifestyle habits has not been fully elucidated and further investigation is required, including a clinical evaluation of the 5-FU efficiency and accompanying side effects. However, the results of the present study suggest that smoking and alcohol consumption may reduce the anticancer activity of 5-FU, possibly through inducing DPD activity. Cigarette smoking and alcohol consumption have long been known as risk factors for head and neck cancers, including oral cancers. It is suggested that a significant proportion of oral cancer patients follow this lifestyle, thus enhancing DPD activity, which subsequently leads to a reduction in 5-FU efficiency. S-1 is a novel, orally administered anticancer agent that is a combination of tegafur, gimeracil and oterasil potassium. Gimeracil is a competitive inhibitor of DPD and maintains efficacious 5-FU concentrations in the plasma and tumor tissues. Therefore, anticancer drugs including DPD inhibitors, such as S-1, may be recomended for cancer patients exhibiting smoking and/or alcohol consumption habits.

\section{Acknowledgements}

This study was supported in part by Grants-in-Aid (2059.2324) for Scientific Research from the Ministry of Education, Culture, Sports, Science and Technology of Japan.

\section{References}

1. Danenberg PV: Thymidylate synthase - a target enzyme in cancer chemotherapy. Biochem Biophys Acta 473: 73-92, 1977.

2. Santi DV, MacHenry CS and Sommer H: Mechanism of interaction of thymidylate synthetase with 5-fluorodeoxyuridylate. Biochemistry 13: 471-481, 1974.

3. Harada K, Kawashima Y, Yoshida H and Sato M: Thymidylate synthase expression in oral squamous cell carcinoma predicts response to S-1. Oncol Rep 15: 1417-1423, 2006.

4. Kawano K, Goto H, Kanda T and Yanagisawa S: Predictive value of immunohistochemical thymidylate synthase expression for histological response to tegafur/uracil (UFT) in oral squamous cell carcinoma. Int J Oral Maxillofac Surg 32: 633-637, 2003.

5. Leichman CG, Lenz HJ, Leichman L, et al: Quantitation of intratumoral thymidylate synthase expression predicts for disseminated colorectal cancer response and resistance to protracted-infusion fluorouracil and weekly leucovorin. J Clin Oncol 15: 3223-3229, 1997.

6. Beck A, Etienne MC, Chéradame S, et al: A role for dihydropyrimidine dehydrogenase and thymidylate synthase in tumor sensitivity to fluorouracil. Eur J Cancer 30: 1517-1522, 1994.

7. Lenz HJ, Leichman CG, Danenberg KD, et al: Thymidylate synthase mRNA level in adenocarcinoma of the stomach: a predictor for primary tumor response and overall survival. J Clin Oncol 14: 176-182, 1996.

8. Hoque M, Kawamata H, Nakashiro K, et al: Dihydropyrimidine dehydrogenase mRNA level correlates with the response to 5-fluorouracil-based chemo-immuno-radiation therapy in human oral squamous cell cancer. Int J Oncol 19: 953-958, 2001.

9. Kobayashi H, Koike T, Nakatsuka A, et al: Dihydropyrimidine dehydrogenase expression predicts survival outcome and chemosensitivity to 5-fluorouracil in patients with oral squamous cell carcinoma. Oral Oncol 41: 38-47, 2005.

10. Etienne MC, Chéradame S, Fischel JL, et al: Response to fluorouracil therapy in cancer patients: the role of tumoral dihydropyrimidine dehydrogenase activity. J Clin Oncol 13: 1663-1670, 1995.

11. Yoshitomi I, Kawasaki G, Yanamoto S and Mizuno A: Orotate phosphoribosyl transferase mRNA expression in oral squamous cell carcinoma and its relationship with the dihydropyrimidine dehydrogenase expression and the clinical effect of 5-fluorouracil. Oral Oncol 42: 880-887, 2006.

12. Peters GJ, Laurensse E, Leyva A, Lankelma J and Pinedo HM: Sensitivity of human, murine, and rat cells to 5-fluorouracil and 5'-deoxy-5-fluorouridine in relation to drug-metabolizing enzymes. Cancer Res 46: 20-28, 1986.

13. Peters GJ, Braakhuis BJ, de Brujin EA, Laurensse EJ, van Walsum $\mathrm{M}$ and Pinedo HM: Enhanced therapeutic efficacy of 5'-deoxy-5-fluorouridine in 5-fluorouracil-resistant head and neck tumors in relation to 5-fluorouracil metabolizing enzymes. Br J Cancer 56: 327-334, 1989.

14. Koizumi W, Saigenji K, Nakamaru N, Okayasu I and Kurihara M: Prediction of response to 5'-deoxy-5fluorouridine (5'-DFUR) in patients with inoperable advanced gastric cancer by immunostaining of thymidine phosphorylase/platelet-derived endothelial cell growth factor. Oncology 56: 215-222, 1999.

15. Sawada N, Ishikawa T, Fukase Y, Nishida M, Yoshikubo T and Ishitsuka H: Induction of thymidine phosphorylase activity and enhancement of capecitabine efficacy by taxol/taxotere in human cancer xenografts. Clin Cancer Res 4: 1013-1019, 1998. 
16. Kawasaki G, Yoshitomi I, Yamamoto S and Mizuno A: Thymidylate synthase and dihydropyrimidine dehydrogenase expression in oral squamous cell carcinoma: An immunohistochemical and clinicopathologic study. Oral Surg Oral Med Oral Pathol Radiol Endod 94: 717-723, 2002.

17. Yang CG, Ciccolini J, Blesius A, et al: DPD-based adaptive dosing of 5-FU in patients with head and neck cancer: impact on treatment efficacy and toxicity. Cancer Chemother Pharmacol 67: 49-56, 2011.

18. Freedman ND, Schatzkin A, Leitzmann MF, Hollenbeck AR and Abent CC: Alcohol and head and neck cancer risk in a prospective study. Br J Cancer 96: 1469-1474, 2007.

19. Browman GP, Wong G, Hodson I, et al: Influence of cigarette smoking on the efficacy of radiation therapy in head and neck cancer. N Engl J Med 328: 159-163, 1993.
20. Yoshida Y, Komatsu M, Ozeki A, Nango R and Tsukamoto I: Ethanol represses thymidylate synthase and thymidine kinase at mRNA level in regenerating rat liver after partial hepatectomy. Biochim Biophys Acta 1336: 180-186, 1997.

21. Lieber CS: Ethanol metabolism, cirrhosis and alcoholism. Clin Chim Acta 257: 59-84, 1997.

22. Yamashita T, Toida M, Kato K, et al: The effect of neoadjuvant therapy on the 5-fluorouracil metabolic and relative enzymes of oral squamous cell carcinoma. Oncol Rep 22: 501-507, 2009.

23. Zevin S, Benowitz NL: Drug interactions with tobacco smoking. An update. Clin Pharmacokinet 36: 425-438, 1999. 